\title{
Hedgehog signaling has a protective effect in glucocorticoid-induced mouse neonatal brain injury through an $11 \beta$ HSD2-dependent mechanism
}

Vivi M. Heine ${ }^{1}$ and David H. Rowitch ${ }^{1,2}$

\begin{abstract}
1Department of Pediatrics and Department of Neurosurgery, Howard Hughes Medical Institute and Institute for Regeneration Medicine, and 2Division of Neonatology, UCSF, San Francisco, California, USA.
\end{abstract}

\begin{abstract}
Glucocorticoids (GCs) are administered to human fetuses at risk of premature delivery and to infants with life-threatening respiratory and cardiac conditions. However, there are ongoing concerns about adverse effects of GC treatment on the developing human brain, although the precise molecular mechanisms underlying GCinduced brain injury are unclear. Here, we identified what we believe to be novel cross-antagonistic interactions of Sonic hedgehog (Shh) and GC signaling in proliferating mouse cerebellar granule neuron precursors (CGNPs). Chronic GC treatment (from P0 through P7) in mouse pups inhibited Shh-induced proliferation and upregulation of expression of $\mathrm{N}$-myc, Gli1, and D-type cyclin protein in CGNPs. Conversely, acute GC treatment (on P7 only) caused transient apoptosis. Shh signaling antagonized these effects of GCs, in part by induc-

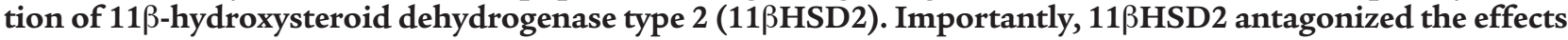
of the GCs corticosterone, hydrocortisone, and prednisolone, but not the synthetic GC dexamethasone. Our findings indicate that Shh signaling is protective in the setting of GC-induced mouse neonatal brain injury. Furthermore, they led us to propose that 11/HSD2-sensitive GCs (e.g., hydrocortisone) should be used in preference to dexamethasone in neonatal human infants because of the potential for reduced neurotoxicity.
\end{abstract}

\section{Introduction}

Respiratory distress syndrome (RDS), caused by surfactant deficiency and lung immaturity, is a serious complication of preterm birth and a significant cause of early neonatal death. Since the 1970s, the synthetic glucocorticoids (GCs) dexamethasone (Dex) and $\beta$-methasone have been prescribed antenatally to the human fetus to prevent RDS and other complications of prematurity (1, $2)$. GCs are also used postnatally in neonates with life-threatening airway and pulmonary conditions as well as in children that require cardiac bypass. However, there is ongoing concern about detrimental effects of GCs on the developing brain that lead to cognitive impairment and cerebral palsy (3-5), particularly in infants who receive Dex in the postnatal period (6).

The molecular basis for GC-induced injury in the developing brain remains poorly understood. GCs generally exert their action through intracellular receptors, the mineralocorticoid receptor (MR) and the GC receptor (GR), which belong to a nuclear receptor superfamily that regulates gene expression in a ligand-dependent manner (7). The 2 receptors are characterized by, among other things, their differential ligand affinity (8), and a phosphorylation/dephosphorylation mechanism is responsible for the level of active receptor in the

Conflict of interest: The authors have declared that no conflict of interest exists. Nonstandard abbreviations used: Casp3, caspase-3; CBX, carbenoxolone; CGNP, cerebellar granule neuron precursor; CldU, chlorodeoxyuridine; Cort, corticosterone; Dex, dexamethasone; EGL, external granule layer; GC, glucocorticoid; GR, GC receptor; $11 \beta \mathrm{HSD}, 11 \beta$-hydroxysteroid dehydrogenase; IdU, iododeoxyuridine; IGL, internal granule layer; $\mathrm{MR}$, mineralocorticoid receptor; $\mathrm{pH} 3$, phospho-histone $\mathrm{H} 3$; Pred, prednisolone; Ptch, Patched; Shh, Sonic hedgehog; Smo, Smoothened; SmoM2, conditionally active Smoothened allele.

Citation for this article: J. Clin. Invest. 119:267-277 (2009). doi:10.1172/JCI36376. cell (9). A NAD-dependent high-affinity enzyme involved in the local metabolic inactivation of endogenous GCs into inert 11-keto derivatives, $11 \beta$-hydroxysteroid dehydrogenase type 2 (11ßHSD2), acts in opposition to $11 \beta$ HSD1, which converts substrate into active corticosterone (Cort). Dex and $\beta$-methasone can cross the placenta to the fetus because they have a low affinity for cortisol-binding globulin and they are not inactivated by $11 \beta \mathrm{HSD} 2$, which is expressed at high levels in placenta. In contrast, Cort and prednisolone (Pred) are susceptible to inactivation by $11 \beta \mathrm{HSD} 2$ activity. $11 \beta H S D 2$ is expressed in the developing CNS, including in cerebellar granule neuron precursors (CGNPs) (9), where its function is necessary for normal cerebellar development (10). Animal studies reveal that antenatal and neonatal exposure to supraphysiologic levels of GCs, analogous to treatments in humans, results in delayed and/or abnormal development of the cerebellum (11) and increased apoptosis of CGNPs (12), indicating that the cerebellum is a suitable model system to study adverse effects of GCs on brain development.

Cerebellar development is initiated in the embryonic mammalian brain, but its major growth phase occurs in late gestation and continues through the neonatal period. Granule neurons are the most numerous cells in the cerebellum. During development, CGNPs comprise the external granule layer (EGL) of the cerebellum and proliferate extensively under control of Sonic hedgehog (Shh) proteins that are produced by Purkinje cells (13). In rodents, CGNPs undergo their major expansion from P0 to P14, while in humans, cerebellar growth continues until at least 1 year of age (14). Binding of Shh to the 12-pass transmembrane receptor Patched (Ptch) releases Ptch inhibition of the G-protein coupled 7-pass receptor, Smoothened (Smo), which activates transcription of Hedgehog gene targets. The protooncogene $\mathrm{N}$-myc is thought to 


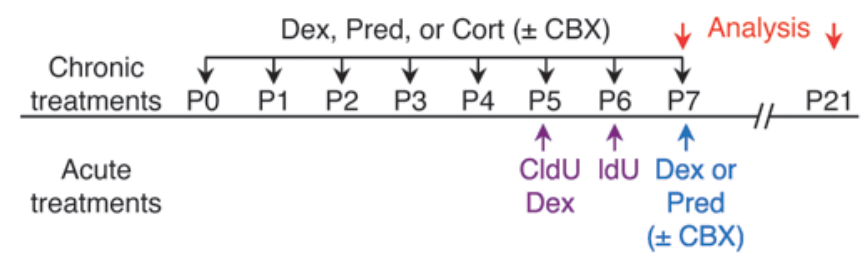

Figure 1

Timing of chronic and acute treatment protocols. Chronic GC administration from P0 to P7 is shown in black; acute GC treatment at P7 is shown in blue; administration of thymidine analogs CldU and IdU is shown in purple. Dex was given $2 \mathrm{~h}$ after CldU. Pups were analyzed to determine weight gain at P7 and P21 (see Table 1).

be one of the key Shh targets regulating CGNP cell cycle progression $(15,16)$. Other targets involved in normal cell cycle control in the developing cerebellum include the Gli zinc finger proteins (17) and forkhead protein FoxM1 (18).

Here we report that chronic GC signaling antagonized Shhinduced proliferation and upregulation of N-myc, Gli1, and D-type cyclin protein levels in CGNPs. Conversely, we found that Shh signaling was a potent inducer of $11 \beta \mathrm{HSD} 2$, but not $11 \beta \mathrm{HSD} 1$, and counteracted GC effects in vivo in part by this mechanism. Indeed, in Math1cre,SmoM2 transgenic animals, which express a conditionally active Smoothened allele (SmoM2), CGNP proliferation was protected from effects of Pred and Cort but not of the 11ßHSD2insensitive GC Dex. We also found that transient CGNP-associated apoptosis that occurred 6-9 h after acute GC treatment was mitigated by SmoM2. Such resistance to antiproliferative and proapoptotic effects of Pred was reversed by coadministration of the $11 \beta H S D$ inhibitor carbenoxolone (CBX). Together, our findings indicate that Shh signaling protects against GC-induced cerebellar injury through an 11ßHSD2-dependent mechanism.

\section{Results}

GC treatment inhibits cerebellar growth and CGNP proliferation. Previous studies have indicated that GC treatment results in decreased cerebellar volumes in the rodent and human brain $(19,20)$. To confirm the effects of GC treatment on early neonatal cerebellar development involving multiple courses, we treated C57BL/6J mouse pups with Dex daily for 1 week from P0 to P7 (Figure 1). Treatment from P0 to P7 is referred to herein as chronic; single treatment at P7 is referred to herein as acute. We used a dose of $0.1 \mathrm{mg} / \mathrm{kg} \mathrm{Dex}$, within the range $(0.1-0.5 \mathrm{mg} / \mathrm{kg})$ used for human neonates in the United States. As shown in Table 1, at P7 pups treated with Dex showed significantly reduced body weight gain $(P<0.006)$, and by comparing cerebellar weights with whole brains, we found that the cerebella of the Dex-treated animals were markedly and disproportionately small $(P<0.00001)$. Persistent, selective impairment of cerebellar growth remained significant at P21 ( $P=0.037$; Table 1$)$. The P7 cerebellum showed morphological changes in the Dextreated mice, evident especially in lobes II-VII (Figure 2, A and E).

The mouse cerebellum undergoes its major proliferative phase from P0 to P14, attributable mainly to expansion of CGNP populations in the EGL. Area measurements using Object-Image, an extended version of NIH Image (see Methods), showed a significant decrease in the volume of the EGL - which is composed of proliferative CGNPs - in Dex-treated versus vehicle-treated mice $(P<0.0000001$, Figure 2I). In addition, the EGL area relative to the internal granule layer (IGL), the cell layer composed of postmi- totic granule cells, was significantly decreased $(P=0.001$, Figure $2 J)$, suggesting higher relative numbers of differentiated to undifferentiated CGNPs in the Dex-treated animals. To further examine the effects of chronic Dex treatment on CGNP cell cycle regulation in vivo, we quantified the mean number of mitotically active phospho-histone $\mathrm{H3}$-positive $\left(\mathrm{pH}^{+}\right)$cells in the EGL per sagittal section (21-23), and found that the number of cells significantly decreased in Dex-treated animals (Figure 2, B, F, and K). Thus, the population of proliferating CGNPs is decreased by chronic Dex treatment using 2 independent measures.

Because our protocol for GC administration began at P0, we were able to confirm that both Cort and Pred had effects similar to those of to Dex in WT mice, resulting in significantly decreased levels of mitotic activity compared with vehicle control (Pred, $P<0.001$; Cort, $P<0.01$; ANOVA with Tukey's post-hoc; Figure $2 \mathrm{~K})$. Appropriate dose adjustment for the various GCs was used (24). To control for the longer half-life of Dex versus Pred (or Cort) and therefore a possible buildup of GCs over $7 \mathrm{~d}$ of treatment, serum levels were measured $24 \mathrm{~h}$ after the P0 and P7 doses; we found that levels of Dex were not significantly different (data not shown). Nevertheless, Dex had a relatively more potent antimitotic effect (45\% decrease) than did Pred (30\% decrease; NS) or Cort (22\% decrease; $P<0.01$, ANOVA with Tukey's post-hoc).

We next analyzed apoptosis after chronic Dex treatment by immunocytochemistry for caspase-3 (Casp3; Figure 2, C and G) and TUNEL assay (Figure 2, D and H). Dex-treated animals trended toward a lower number of Casp $3^{+}$cells $(P=0.08)$ and contained significantly lower numbers of TUNEL ${ }^{+}$cells than did vehicle-treated mice $(P<0.04$; Figure 2L). Recent findings indicate that CGNPs of P4-P10 mice are vulnerable to apoptotic effects of acute Dex treatment $(0.3-3 \mathrm{mg} / \mathrm{kg} / \mathrm{dose}$; ref. 12). In keeping with this, we found that animals receiving acute Dex treatment $(0.1 \mathrm{mg} / \mathrm{kg})$ at $\mathrm{P} 7$ showed a timelimited phase of increased apoptosis compared with vehicle 6-9 h after injection ( 6 h, $P<0.001$; 9 h, $P<0.05$; ANOVA with Tukey's post-hoc), as well as decreased proliferation $(P<0.0001$, ANOVA; Figure $2 \mathrm{M})$. In contrast, chronically Dex-treated pups $(0.1 \mathrm{mg} / \mathrm{kg})$ studied at P0, P3, P5, and P7 did not show significant cell death $6 \mathrm{~h}$ after the final injection prior to harvest (Figure $2 \mathrm{~N}$ ). Together, these data indicate distinct acute and chronic effects of GC treatment at the doses we tested: whereas acute treatment at P7 causes apoptosis and decreased proliferation, chronic treatment affects primarily CGNP proliferation, and proapoptotic effects are insignificant.

\section{Table 1}

Effect of chronic Dex treatment of mouse pups on body weight gain at $P 7$ and $P 21$

\begin{tabular}{lccc}
\hline & Saline & Dex & $\boldsymbol{P}$ \\
P7 $(\boldsymbol{n})$ & $\mathbf{6}$ & $\mathbf{1 6}$ & \\
Body wt $(\mathrm{mg})$ & $3,640 \pm 830$ & $2,830 \pm 550$ & $<0.006$ \\
Whole brain wt $(\mathrm{mg})$ & $260.8 \pm 18.6$ & $202.9 \pm 34.5$ & $<0.001$ \\
Cerebellum wt $(\mathrm{mg})$ & $42.0 \pm 5.6$ & $19.6 \pm 4.9$ & $<0.0000001$ \\
Brain/cerebellum ratio & $6.3 \pm 0.6$ & $10.6 \pm 1.6$ & $<0.00001$ \\
P21 $(\boldsymbol{n})$ & $\mathbf{1 3}$ & $\mathbf{1 0}$ & \\
Body wt $(\mathrm{g})$ & $10.56 \pm 0.87$ & $9.32 \pm 2.29$ & 0.13 \\
Whole brain wt $(\mathrm{mg})$ & $423.6 \pm 12.7$ & $378.3 \pm 29.1$ & 0.0006 \\
Cerebellum wt $(\mathrm{mg})$ & $53.4 \pm 7.4$ & $40.7 \pm 4.6$ & 0.0001 \\
Brain/cerebellum ratio & $8.1 \pm 1.2$ & $9.2 \pm 1.2$ & 0.037 \\
\hline
\end{tabular}

Data are mean \pm SD. 

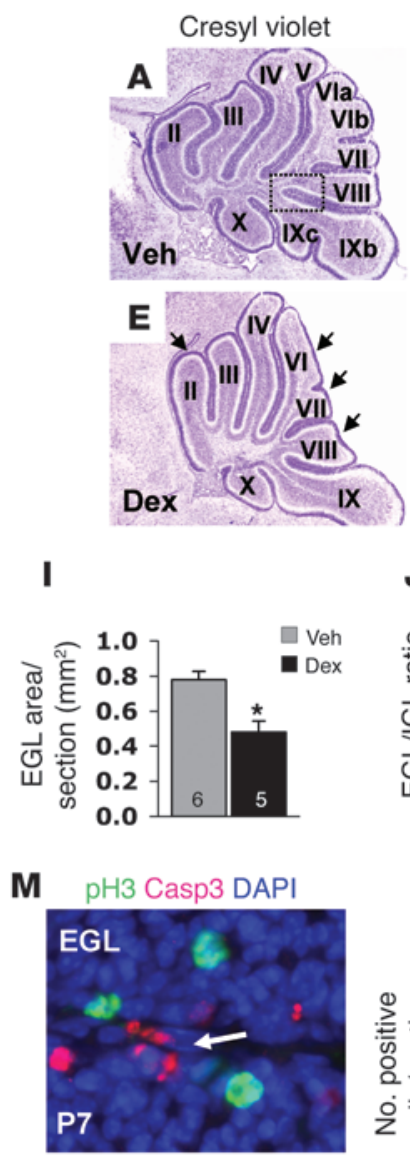

Acute $\operatorname{Dex}(6 \mathrm{~h})$

$\mathbf{0}$

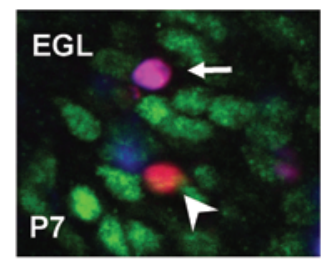

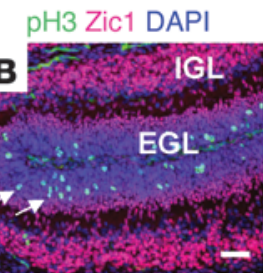
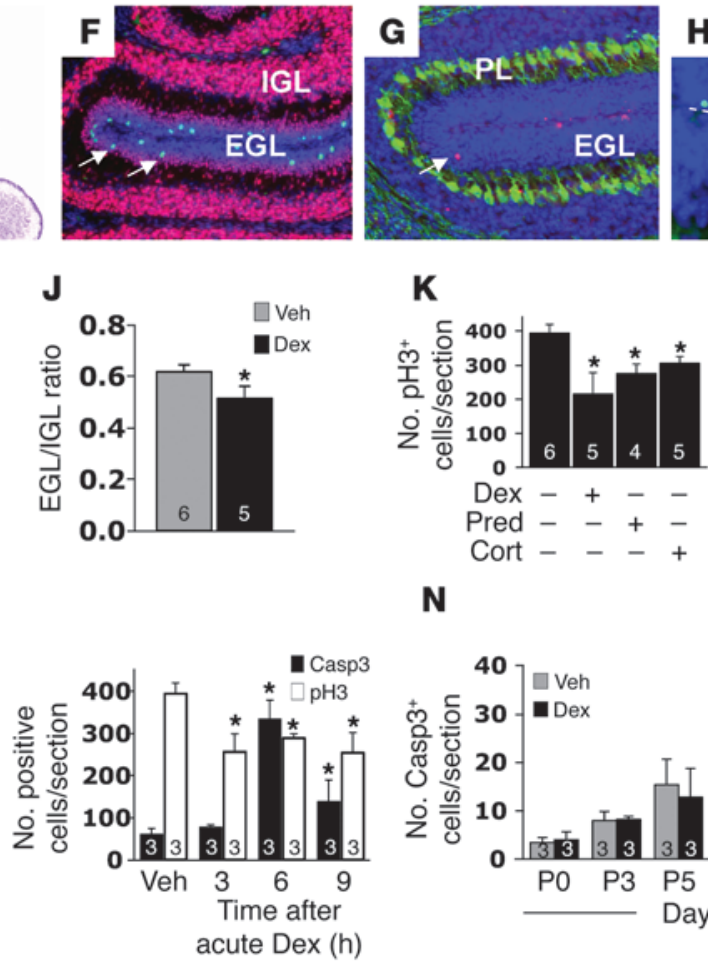

$\mathbf{N}$
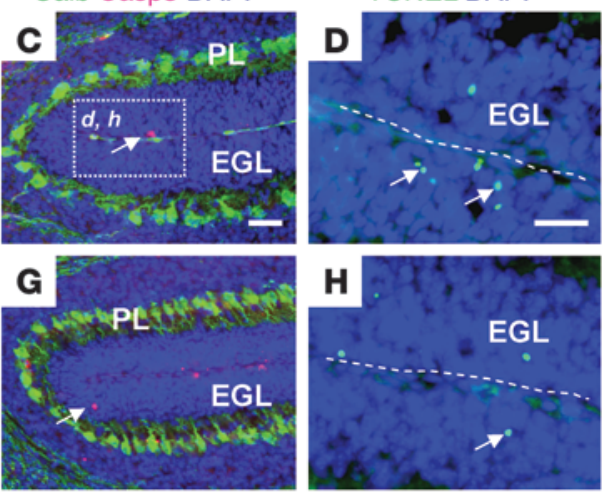

$\mathbf{K}$
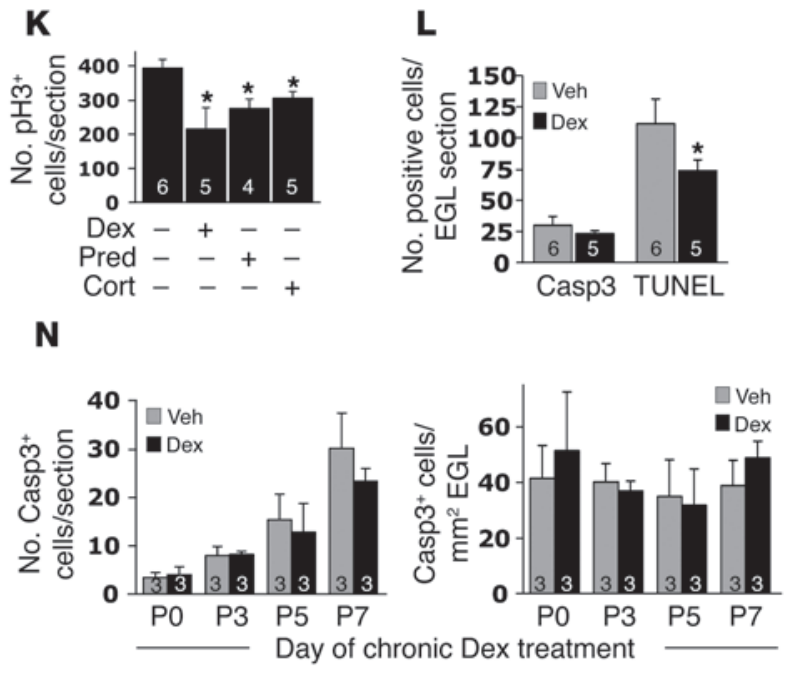

$\mathbf{P}$
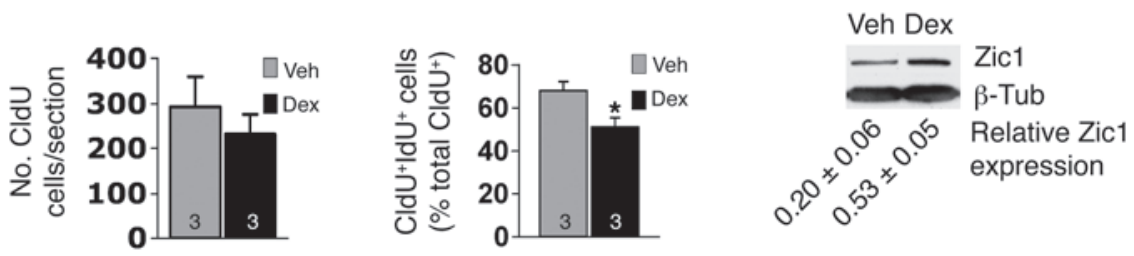

Figure 2

Dex treatment inhibits neonatal granule cell precursor proliferation. (A-H) P7 mouse pups were treated with vehicle (Veh; A-D) or Dex (E-H). (A and E) Chronic Dex treatment disrupted cerebellar foliation in lobes II-VII (arrows). Original magnification, $\times 20$. The boxed region in $\mathbf{A}$ is shown at higher magnification in B, C, F, and G. (B and F) Immunocytochemistry for Zic1 and pH3 (arrows). (C and G) Immunocytochemistry for Casp3 (arrows). Dex did not change the mean total number of Calbindin-positive Purkinje cells (not shown). PL, Purkinje cell layer. The boxed region in $\mathbf{C}$ is shown at higher magnification in $\mathbf{D}$ and $\mathbf{H}$. (D and $\mathbf{H})$ TUNEL assay. Dotted lines denote the outer border of the EGL. (I and $\mathbf{J})$ Mean EGL surface area per section (I) and proportional to the IGL (J). (K) $\mathrm{pH} 3^{+}$cells per sagittal section of mice treated with vehicle, Dex, Pred, or Cort. (L) Number of apoptotic cells in the EGL. (M) Number of $\mathrm{Casp3}^{+}$and $\mathrm{pH}^{+}$cells after acute treatment. Original magnification, $\times 1,000$. (N) Casp3 ${ }^{+}$ cells during chronic treatment, both total number and per $\mathrm{mm}^{2} \mathrm{EGL}$. (O) Dex treatment $2 \mathrm{~h}$ after CldU injection (see Figure 1) did not affect the number of $\mathrm{CldU}^{+}$cells, but significantly decreased the number of CldU+ldU+ cells. Original magnification, $\times 1,000$. (P) Western blot analysis of protein lysates of whole cerebella. Zic1 protein levels, shown as estimated mean \pm SD number of cells per sagittal section, significantly increased after Dex treatment $(P<0.01)$. Scale bars: $100 \mathrm{~mm}$. For each group, $n$ is shown within the corresponding bar. Asterisks denote significant differences versus respective vehicle groups; exact $P$ values are shown in Results.

To address whether Dex also causes premature CGNP cell cycle exit, we used sequential labeling of cells in S-phase with the thymidine analogs chlorodeoxyuridine (CldU) and iododeoxyuridine (IdU) (25). Starting at P5, a pulse of $42.5 \mu \mathrm{g} / \mathrm{g}$ CldU was administered to the pups, followed by Dex or saline 2 h later. On P6, pups received an equimolar dose of $57.5 \mu \mathrm{g} / \mathrm{g}$ IdU, and on P7 they were perfused for analysis (Figure 1 and Figure 2O). The population of $\mathrm{CldU}^{+}$cells was similar in both groups $(P=0.27$; Figure $2 \mathrm{O}$ ), which indicates that CldU-labeled cells were not removed by Dex-induced apoptosis. Interestingly, however, we observed sig- 
GR

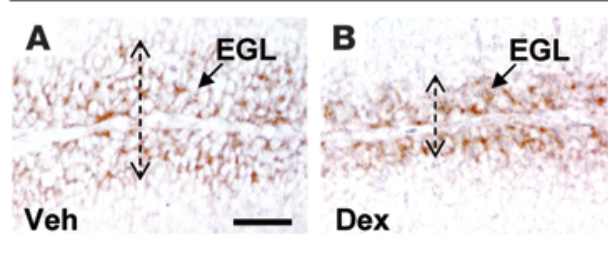

Shh
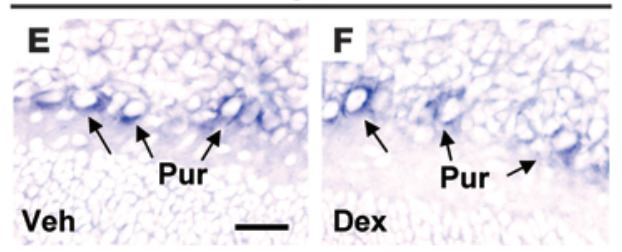

$M R$

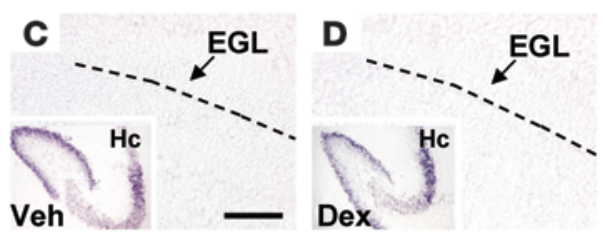

Gli1

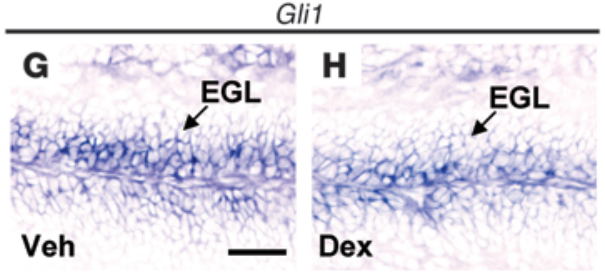

Figure 3

Chronic Dex treatment causes decreased GR expression but does not affect Shh and Gli1. (A and B) CGNPs in the EGL have high expression of the GR. Immunocytochemistry for GR of the Dex-treated cerebellum indicates the decreased surface area of the EGL, as shown in Figure 2E. The width of the EGL is shown by dotted lines. ( $\mathbf{C}$ and $\mathbf{D}) M R$ was not expressed in the cerebellum. Dotted lines denote the outer border of the EGL. Hc, hippocampus. Original magnification of insets, $\times 40$. (E-H) There was no change in Shh and Gli1 expression, as demonstrated by in situ hybridization of Shh-expressing (E and $\mathbf{F}$ ) Purkinje (Pur) and Gli1-expressing ( $\mathbf{G}$ and $\mathbf{H}$ ) granule cells in vehicle- and Dex-treated mouse pups. Scale bars: $100 \mu \mathrm{m}$.

nificantly lower colabeling with IdU in the Dex-treated animals $(P<0.01$; Figure 2O). Thus, Dex evidently prevented cycling cells from picking up the second pulse label, consistent with the possibility that they were pushed to precociously leave the cell cycle. Accelerated granule cell differentiation was further suggested by quantitative assessment of levels of Zic1 protein, a mature lineage marker. We observed increased relative Zic1 expression in the Dextreated mice at P7 $(P<0.01$, Figure $2 \mathrm{P})$, coupled with decreased EGL volume indicative of enhanced differentiation. Together with the decreased EGL/IGL ratio (Figure 2J), these findings suggest that GCs act primarily to inhibit proliferation and promote CGNP cell cycle exit and premature differentiation. This results in a decrease in ultimate granule neuron numbers, as has been observed in previous studies $(12,26)$.

Dex treatment does not alter expression of $G R, M R$, Shb, or its transcriptional target, Gli1. At P7, CGNPs of the EGL showed robust expression of the intracellular GR (Figure 3, A and B), whereas the $M R$ was not expressed (Figure 3, C and D), which suggests that GR is the major mediator of GC effects in developing cerebellum at the stages analyzed. GR and MR expression in the EGL was not substantially affected by chronic treatment with Dex.

To further investigate the basis for antiproliferative GC effects in the neonatal cerebellum, we focused on Shh signaling, the major mitogenic pathway for expansion of CGNPs (13). Although GCs can have negative effects on Purkinje cell populations (27), the principal source of Shh proteins in developing cerebellum (13), we found that Dex treatment had no significant effect on the number of calbindinpositive Purkinje cells $(P=0.60$; Figure 2, $\mathrm{C}$ and $\mathrm{G})$. Indeed, expression of Shb and its transcriptional target Gli1 was not affected in Dex-treated animals at P7 (Figure 3, E-H). Thus, GCs do not detectably affect either Shh production or Shh signaling in Purkinje cells or CGNPs, respectively. These findings suggest that, in contrast to cyclopamine and other direct Smo inhibitors (28), GCs might act downstream of Smo in the Hedgehog pathway in CGNPs.
GCs inhibit mitogenic effects of Shb on CGNPs in vitro. We next asked whether GC treatment antagonized direct mitogenic effects of Shh in CGNP primary cultures (15). As shown in Figure 4B, maximal proliferation of Shh-treated CGNPs was significantly inhibited $(P<0.05$, ANOVA) in a dose-dependent fashion by $2-40 \mu \mathrm{M}$ Dex for $24 \mathrm{~h}$, but not by Pred $(P=0.57$, ANOVA). Shh signaling promotes CGNP proliferation in part through upregulation of $\mathrm{N}$-myc and D-type cyclin protein levels (15). To assess the impact of GC treatment on Shhinduced cell cycle regulatory factors, nondenaturing lysates were prepared from CGNP cultures treated with $40 \mu \mathrm{M}$ Dex for $24 \mathrm{~h}$. Dex treatment resulted in decreased levels of cyclin D1 protein expression compared with vehicle-treated cultures (Figure 4D), which indicates inhibition of CGNP proliferation. In addition, the decrease in cyclin D2, N-myc, and Gli1 protein (Figure 4D) indicates that Dex interferes with the Smo pathway. Dex-treated cultures also showed decreased expression of the GR, consistent with previous reports of GR downregulation upon activation (29).

Smo activation antagonizes antiproliferative effects of GCs in CGNPs. The level of Shh pathway activation has previously been shown to regulate cerebellar foliation (30), raising the possibility that increased levels of Shh-Smo signaling might counteract antiproliferative effects of GC treatment. To increase levels of Shh-Smo signaling in CGNPs, we generated transgenic mice in which constitutively activated Smo (SmoM2 ${ }^{\ell / f f}$; ref. 31) is produced specifically in CGNPs under the control of Math1cre (18). In contrast to WT CGNP cultures, the number of $\mathrm{pH}^{+}$cells in the Math1cre,SmoM2 CGNP cultures was unaffected by treatment with Dex up to $40 \mu \mathrm{M}$ (Figure 4, A and B). Furthermore, Western blot analysis showed elevated cyclin D1 and cyclin D2 protein levels despite $40 \mu \mathrm{M}$ Dex treatment (Figure 4E). At 60-160 $\mu \mathrm{M}$ Dex, numbers of $\mathrm{pH}^{+}$cells in the Math1cre,SmoM2 cultures were reduced in a dose-dependent fashion compared with vehicle-treated cells $(P<0.0001$, ANOVA; Figure 4C). In contrast, Math1cre,SmoM2 cultures were resistant to high doses of Pred $(120 \mu \mathrm{M}, \mathrm{NS} ; 140 \mu \mathrm{M}$, $P<0.05$; ANOVA with Tukey's post-hoc). We conclude that constitutively activated Smo in CGNPs protects against antiproliferative effects of GCs and that resistance to Pred is relatively high compared with resistance to Dex.

We have previously shown that $\mathrm{N}$-myc is a direct transcriptional target of Shh signaling in CGNP (15). In the present study, quantitative PCR analysis revealed that N-myc and Gli1 transcriptional upregulation by Shh was unaffected in Dex-treated WT or Math1cre,SmoM2 CGNPs (Figure 5, A and B). Taken together with the data in Figure 4, these findings suggest that GC signaling antagonizes proliferative effects of Shh in CGNPs as a result of inhibited upregulation of N-myc, Gli1, and D-type cyclin protein levels.

Expression of 11BHSD2, which encodes a potent $G C$ antagonist enzyme, is upregulated by Shb-Smo signaling. Given our finding that Shh-Smo signaling antagonized the antiproliferative effects of chronic 
A
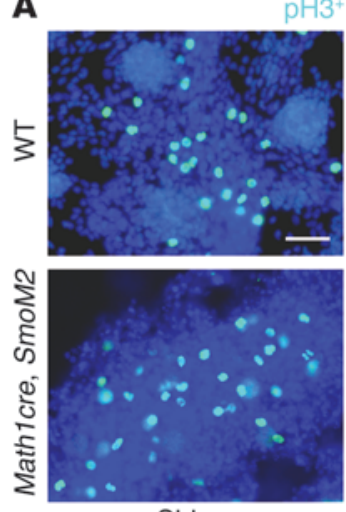

Shh

D

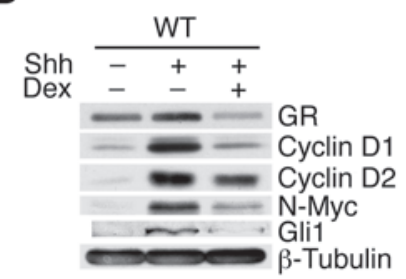

B
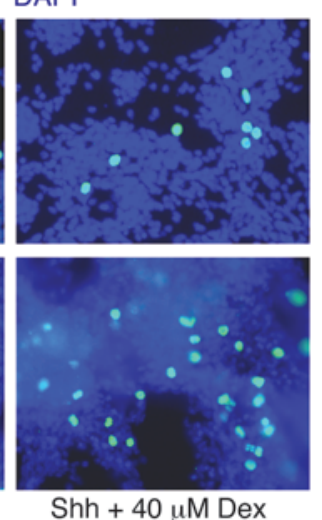

E

C
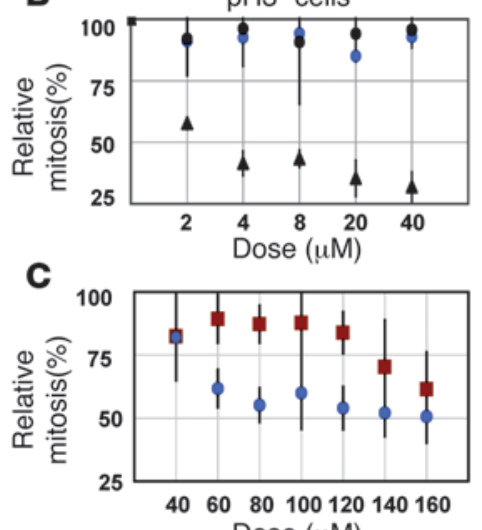
Dose $(\mu \mathrm{M})$
Figure 4

Cross-antagonistic Shh-GC signaling regulates CGNP proliferation in vitro. (A) Immunocytochemistry for $\mathrm{pH} 3$ of CGNP cultures, generated from WT or Math1cre,SmoM2 animals, and treated with Shh alone or in combination with $40 \mu \mathrm{M}$ Dex. (B) To determine the optimal dose to inhibit CGNP proliferation, cultures were exposed to different doses of Dex and Pred for $24 \mathrm{~h}$. The number of $\mathrm{pH}^{+}$ cells in the WT cultures significantly decreased with increasing Dex (black triangles) and were unaffected by Pred (black circles). The number of $\mathrm{pH}^{+}$cells in the Math1cre,SmoM2 cultures were not affected up to $40 \mu \mathrm{M}$ Dex (blue circles). (C) At 60-160 $\mu \mathrm{M}$ Dex, the number of pH3 ${ }^{+}$ cells in the Math1cre,SmoM2 cultures was dose-dependently affected (blue circles). Conversely, Math1cre,SmoM2 cultures were protected against Pred up to $120 \mu \mathrm{M}$ (red squares). (D) Protein lysates were prepared from CGNPs treated with vehicle, Shh, or Shh plus $40 \mu \mathrm{M}$ Dex for $24 \mathrm{~h}$. Western blot analysis showed that Dex treatment decreased cyclin D1, N-myc, Gli1, and cyclin D2 protein expression. (E) Western blot analysis of Math1cre,SmoM2 CGNPs showed that cyclin D1 levels were greatly upregulated, independent of Shh administration, and were unchanged after $40 \mu \mathrm{M}$ Dex treatment. Furthermore, cyclin D2, Gli1, and N-myc levels were unchanged. Samples were run on the same gel but were noncontiguous. Scale bar: $50 \mu \mathrm{m}$. Exact $P$ values are shown in Results.

cate that Shh-Smo pathway activation upregulates $11 \beta H S D 2$ expression and that levels are augmented in CGNPs of Math1cre,SmoM2 mice. Furthermore, we found that $11 \beta \mathrm{HSD} 1$ was not expressed in CGNPs during the P0-P7 time frame, which indicates that only $11 \beta \mathrm{HSD} 2$ is active in developing CGNPs. Our findings do not establish whether $11 \beta H S D 2$ upregulation by Shh-Smo signaling is direct or indirect.

Hedgehog signaling antagonizes GC inbibition of CGNP proliferation in vivo in an 11ßHSD2-dependent manner. We next tested whether increased levels of Shh-Smo signaling antagonize GCs in vivo. Untreated Math1cre,SmoM2 mice showed an expanded, highly proliferative EGL at P7 (Figure 6A). Dex treatment significantly decreased the number of dividing cells in the EGL of Math1cre,SmoM2 mice $(P<0.05$, ANOVA with Tukey's post-hoc; Figure $6 \mathrm{~B})$. However, the $25 \%$ reduction was clearly blunted compared with the 50\% decrease observed in WT mice (Figure $2 \mathrm{~K}$ ), indicating that Smo activation is partially effective at counteracting Dex-induced inhibition of CGNP proliferation in vivo. In dramatic contrast, we found full rescue of proliferation levels when animals were treated with either Pred or Cort (compare Figure $2 \mathrm{~K}$ and Figure $6 \mathrm{~B})$.

Because Math1cre,SmoM2 mice showed dramatically upregulated $11 \beta H S D 2$ expression, we tested whether increased $11 \beta$ HSD2 activity accounted for resistance to Pred or Cort using CBX, an $11 \beta$ HSD inhibiGC treatment, we focused on potential Shh-Smo gene targets encoding factors with anti-GC signaling activity. Consistent with previous reports $(9,32)$, we observed differential regulation of several genes of the steroid signaling axis over time in the developing cerebellum between P0 and P60, including midkine, GR, MR, 11ßHSD1, and 11ßHSD2 (A. Kho, V.M., Heine, and D.H. Rowitch, unpublished observations). In WT CGNP cultures, we observed that Shh induced 11ßHSD2 upregulation despite Dex treatment for $24 \mathrm{~h}$ (Figure 5A). Furthermore, cultured CGNPs from Math1cre,SmoM2 animals showed increased 11ßHSD2 expression levels compared with WT mice (Figure 5A), a finding that was confirmed in whole P7 cerebella in vivo (Figure $5 \mathrm{~B}$ ). We confirmed robust expression of $11 \beta H S D 2$ in proliferating P7 CGNPs in situ (Figure 5C) and that its expression is downregulated with CGNP cell cycle exit, as previously demonstrated (10).

$11 \beta H S D 1$ together with GR has its role in regulating GC action primarily during adulthood (9). However, in contrast to our results with $11 \beta H S D 2,11 \beta H S D 1$ expression was undetectable by RT-PCR in Shh-treated CGNP primary cultures in the presence or absence of Dex, or in P7 mouse cerebella (Figure 5B). These results indi- tor (33). We first exposed Math1cre,SmoM2 cultures to $80 \mu \mathrm{M}$ Dex, an antimitotic dose, or $80 \mu \mathrm{M}$ Pred, a dose that did not affect mitotic activity (see Figure 4). Rajan et al. previously showed that CBX administered at a dose of $1 \mu \mathrm{M}$ inhibits $11 \beta \mathrm{HSD}$ activity in primary hippocampal neuronal cultures (34). As shown in Figure $6 \mathrm{C}$, we found that this dose did not affect proliferation levels in Math1cre,SmoM2 CGNP primary cultures. In both the presence and the absence of CBX, $80 \mu \mathrm{M}$ Dex caused a similar, significant reduction of $\mathrm{pH}^{+} \mathrm{CGNP}$ cell numbers compared with vehicle treatment $(P<0.001$, ANOVA with Tukey's post-hoc test; Figure 6C). In contrast, when $80 \mu \mathrm{M}$ Pred was used in combination with $1 \mu \mathrm{M}$ CBX, the number of $\mathrm{pH}^{+}$cells significantly decreased compared with the vehicle group in the Math1cre,SmoM2 CGNP cultures $(P<0.001$; ANOVA with Tukey's post-hoc test; Figure 6C).

We next tested whether increased $11 \beta$ HSD2 activity accounted for Shh-induced resistance to GC signaling in vivo. Administration of $100 \mathrm{mg} / \mathrm{kg}$ CBX i.p. to intact male rats has previously been shown to inhibit $11 \beta$ HSD activity in several brain structures, including hippocampus, hypothalamus, and amygdala (35), which indicates that it can cross the blood-brain barrier. Because CBX 
A

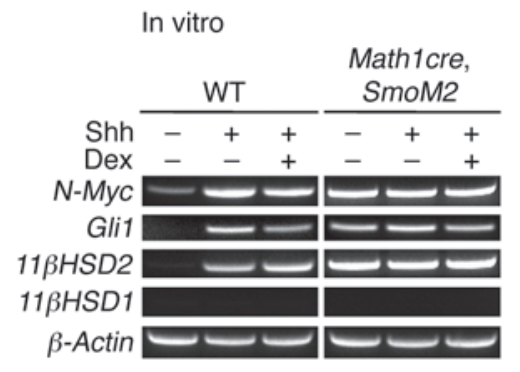

B

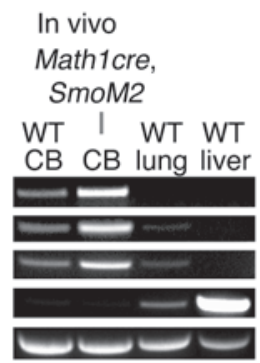

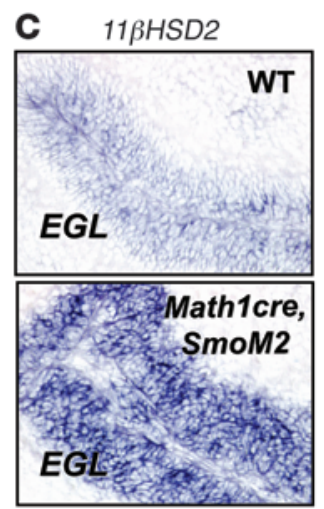

Figure 5

Shh signaling upregulates transcription of $11 \beta H S D 2$ in vitro and in vivo. (A) Whole RNA was isolated from WT and Math1cre,SmoM2 CGNP cultures treated with vehicle, Shh, or Shh plus $40 \mu \mathrm{M}$ Dex for $24 \mathrm{~h}$. Quantitative PCR analysis showed that Shh treatment potently induced the Shh targets $N$-myc and Gli1 as well as $11 \beta H S D 2$ expression in WT CGNP cultures. Math1cre, SmoM2 CGNPs showed increased expression of $N$-myc, Gli1, and $11 \beta H S D 2$ in both vehicle and Shh groups and was unchanged after Dex treatment. $11 \beta H S D 1$ expression was below detectable levels. (B) In vivo, $N$-myc, Gli1, and 11ßHSD2 levels were upregulated in the Math1cre,SmoM2 cerebellum (CB). (C) In situ hybridization showing specific expression of $11 \beta H S D 2$ in the EGL of the P7 WT and Math1cre,SmoM2 cerebellum. Original magnification, $\times 400$.

treatment in neonatal mouse pups might affect EGL growth (33), we first studied the effect of CBX alone on CGNP proliferation at P7. Consistent with our results in vitro (Figure 6C), chronic CBX treatment did not significantly affect CGNP proliferation in Math1cre,SmoM2 mice (Figure 6, D-F). In contrast to results with Pred alone (Figure 6B), CBX treatment combined with Pred resulted in significant inhibition of proliferation $(P=0.001$; Figure $6 \mathrm{E})$ and significantly decreased EGL size $(P<0.05$, ANOVA with Tukey's post-hoc; Figure 6F). Together, these findings show that Smo activation is protective against the chronic antiproliferative effects of GC signaling in an 11ßHSD2-dependent manner.

Shb signaling antagonizes acute GC-induced CGNP apoptosis in an $11 \beta H S D 2-d e p e n d e n t$ manner. To test whether $11 \beta$ HSD2 is protective in acute GC-induced apoptotic injury, we first studied P7 WT mice $6 \mathrm{~h}$ after acute treatment with Pred in the presence or absence of CBX (Figure 1). Pred caused a significant increase in the number of Casp $3^{+}$cells compared with vehicle-treated controls $(P<0.0001)$, and further augmentation compared with Pred alone was achieved by treatment with Pred in combination with CBX $(P<0.01$, ANOVA with Tukey's post-hoc test; Figure 7A). Similar results were observed in quantitative Casp3 protein levels: Pred caused a significant increase versus controls $(P<0.01)$, which was further increased in combination with $\mathrm{CBX}(P<0.05$ versus Pred alone, ANOVA with Tukey's post-hoc test; Figure 7B).

To determine whether activated Hedgehog signaling also protects against GC-induced apoptosis in CGNPs, we subjected Math1cre,SmoM2 mice to acute treatment with Pred or Dex at P7 and tested them $6 \mathrm{~h}$ after injection. Casp3 levels were at baseline and equivalent to vehicle treatment in Pred-treated Math1cre,SmoM2 pups (Figure 7B). In contrast, Casp3 levels were significantly elevated in Dex-treated and Pred plus CBX-treated animals (both $P<0.05$, ANOVA with Tukey's post-hoc; Figure 7B), which suggests that Shh signaling is protective against $\mathrm{GC}$-induced apoptosis in an 11ßHSD2-dependent manner.
Finally, we asked whether $11 \beta$ HSD2 activity accounts for protection against chronic Pred administration in WT mouse cerebellum, as has previously been suggested for Cort (10). We analyzed levels of CGNP proliferation in mice treated chronically with vehicle, Pred, or Pred plus CBX (Figure 7, $\mathrm{C}-\mathrm{E})$. Interestingly, Pred and CBX alone both significantly decreased $\mathrm{pH}^{+}$cells $(P<0.001$ and $P<0.01$, respectively), and, when given in combination, a further significant depression was observed $(P<0.01$ versus CBX and $P<0.05$ versus Pred, ANOVA with Tukey's post-hoc test; Figure 7D). Comparable significant changes were found after measuring the EGL volume $(P<0.0001$ versus CBX and Pred alone, ANOVA with Tukey's posthoc test; Figure 7E). These findings suggest that $11 \beta$ HSD2 activity is protective against endogenous GC signaling as well as chronic Pred treatment.

\section{Discussion}

Despite concerns of adverse effects on the developing human brain, the molecular basis of GC-induced brain injury remains incompletely understood. Of equal concern is our lack of perspective on the endogenous neuroprotective pathways that could be recruited to counteract such GC side effects. Our present findings reveal a surprising intersection between GC signaling and the Hedgehog pathway and provide a basis for understanding how cerebellar morphogenesis is affected in the setting of supraphysiological doses of GCs, a situation encountered routinely in hospitalized human neonates. Implications of these findings during development and in the clinical setting are discussed below.

CGNP cell cycle regulation by GC signaling. We focused here on the impact of GC signaling in the developing cerebellum because impaired cerebellar growth is a hallmark of severe neurological injury in preterm infants $(5,36,37)$. In keeping with previous findings $(12,38)$, we observed that WT neonatal mice given chronic Dex treatment showed dramatic inhibition of cerebellar size $(60 \%$ of normal) as well as persistent cerebellar deficits at P21. GCs can inhibit proliferation, promote cell cycle exit, and induce apoptosis in several tissues, including the brain (39-44). Indeed, Noguchi et al. recently reported that a single dose of Dex $(0.3-3 \mathrm{mg} / \mathrm{kg})$ causes permanent damage to the granule cell population (12). Our paradigm used multiple lower doses of Dex $(0.1 \mathrm{mg} / \mathrm{kg})$ given over $7 \mathrm{~d}$ to more closely mimic treatment doses that have previously been associated with high rates of cerebral palsy in human neonates (45). Currently it is recommended that chronic drug regimens not be used either antenatally (46) or postnatally (47).

We observed distinct acute and chronic injury responses to GCs. In the acute phase, occurring 6-9 h after $0.1 \mathrm{mg} / \mathrm{kg}$ Dex treatment of naive P7 mice, we were able to capture transient apoptosis, in keeping with other recent findings (12). However, a marked contribution of apoptosis to overall cerebellar growth impairment seems unlikely, because after chronic daily administration of GCs, we observed no increase in apoptosis at P0, P3, P5, or P7. Rather, we found significantly decreased proliferation of CGNPs in the EGL at P7 and evidence for accelerated maturation. Sequential labeling 


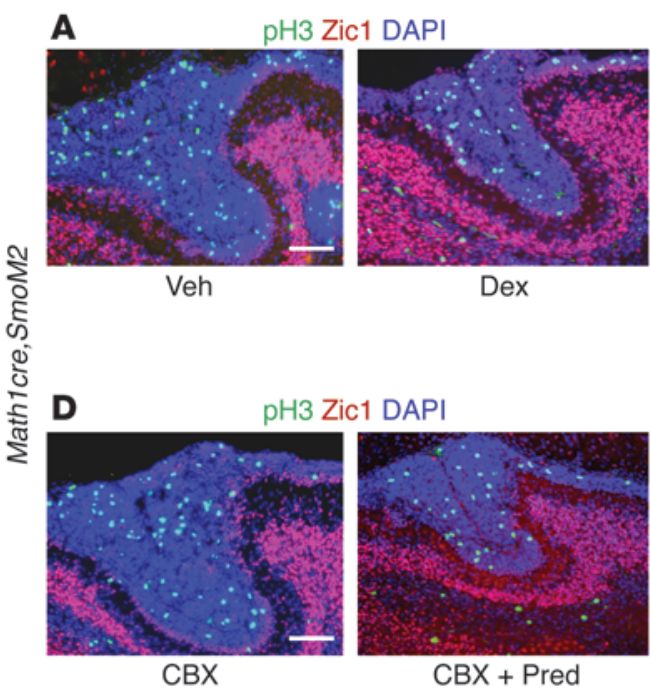

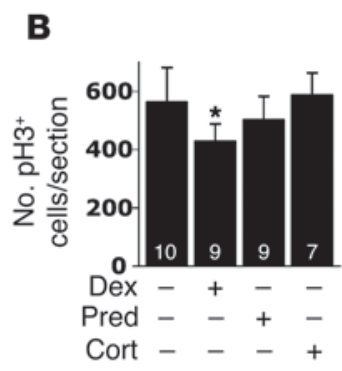

E

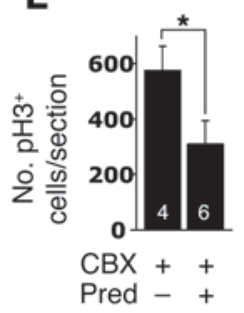

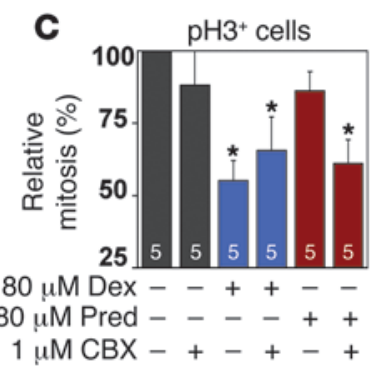

$\mathbf{F}$

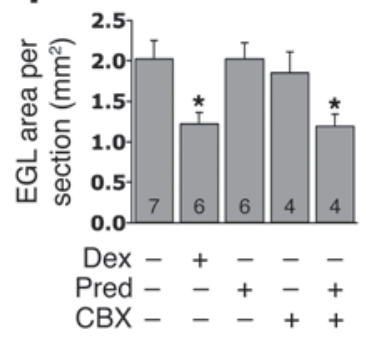

Figure 6

CGNPs in Math1cre,SmoM2 transgenic mice are protected against antiproliferative effects of GCs in an 11ßHSD2-dependent manner in vitro and in vivo. (A) Immunocytochemistry for $\mathrm{pH} 3$ and Zic1 in vehicle- and Dex-treated Math1cre, SmoM2 P7 mice. (B) Mean \pm SD number of pH3 ${ }^{+}$ cells per section in the whole EGL of Math1cre,SmoM2 mice. Animals were protected against Pred and Cort treatment, but only partly so against Dex. (C) To determine whether inhibition of $11 \beta \mathrm{HSD} 2$ by CBX could induce a decrease in CGNP proliferation by $11 \beta \mathrm{HSD} 2-$ sensitive Pred in vitro, Math1cre,SmoM2 cultures were exposed to $80 \mu \mathrm{M}$ Dex or Pred in the presence or absence of CBX. The number of pH3 $3^{+}$cells significantly decreased when CBX was added to $80 \mu$ M Pred. (D) Similar to A, with Math1cre, SmoM2 P7 mice treated with CBX alone or in combination with Pred. (E) Treatment of Pred in combination with $\mathrm{CBX}$ resulted in significantly decreased numbers of $\mathrm{pH} 3^{+}$cells. (F) Area measurements showed that the mean surface area of the EGL also significantly decreased in pups treated with Dex and with Pred plus CBX. Scale bars: $100 \mu \mathrm{m}$. For each group, $n$ is shown within the corresponding bar. Asterisks denote significant differences versus respective vehicle groups (brackets denote comparisons other than with vehicle); exact $P$ values are shown in Results.

of CGNPs in vivo with CldU and IdU suggested that Dex promotes transition from a self-renewing cell to one that more rapidly leaves the cell cycle. The observation of a significant decrease of doublepositive $\mathrm{CldU}^{+} \mathrm{IdU}^{+}$cells to single-positive $\mathrm{CldU}^{+}$cells as a result of Dex treatment is consistent with the possibilities that (a) CGNP cell cycle length is increased or (b) CGNPs leave the cell cycle rather than undergo a further round of division in response to Dex. Indeed, we found that the EGL volume relative to the IGL was significantly decreased and that levels of Zic1, a marker of postmitotic granule cells, were enhanced by Dex, while overall numbers of mature granule cells were reduced compared with untreated animals. Together, our findings indicate that neonatal GC treatment inhibits Shh-dependent proliferation of CGNPs and promotes their maturation, ultimately resulting in decreased numbers of mature granule cells and impaired cerebellar size.

Cross-antagonistic interactions of Hedgehog and GC signaling. Hedgehog signaling has multiple roles during CNS development, including neural tube patterning, development of neuron and glial subtypes, and axon guidance (48). At later stages, Shh is the principal mitogen driving proliferation of CGNPs (13), the most abundant neuron subtype in the brain. Here we report the finding, which we believe to be novel, that the growth inhibitory effects of GCs on CGNPs were attributable to inhibition of Shh signaling. This finding helps explain the molecular basis for GC effects on the developing cerebellum. We found no changes in Shb mRNA expression or in Purkinje cell numbers and therefore hypothesized that GCs affect CGNP development downstream of Shh-Smo signaling. Indeed, we found that upregulated expression of the Shh gene targets N-myc and Gli1
$(15,49)$ was unaffected by Dex treatment, but that levels of $\mathrm{N}$-myc and Gli1 proteins were diminished, indicating that GC signaling might inhibit production and/or stability of N-myc and Gli1 proteins. Dex also inhibited upregulation of D-type cyclin proteins by Shh, most likely as a consequence of effects on N-myc and Gli1. Conversely, Math1cre,SmoM2 animals, which show greatly increased levels of 11ßHSD2, were protected from GC-induced antiproliferative and proapoptotic effects with Cort and Pred treatment but not with treatment by the $11 \beta \mathrm{HSD} 2$-insensitive GC Dex. Interestingly, cultured Math1cre,SmoM2 CGNPs, in contrast to WT cultures, proliferated robustly despite $40 \mu \mathrm{M}$ Dex treatment, which suggests that ShhSmo signaling may regulate additional mechanisms antagonistic to GCs that are $11 \beta$ HSD2 independent. Together, our data revealed cross-antagonistic Shh-GC signaling interactions in the developing cerebellum (Figure 8). Hedgehog-GC interactions might be relevant in additional normal/developmental and/or pathological circumstances. For instance, further work is needed to determine whether Shh signaling in the hippocampus has a similar role in protection of resident neural stem cell populations (50) against effects of GCs.

Hedgehog-induced antagonism of GC signaling is $11 \beta H S D 2$ dependent. $11 \beta \mathrm{HSD} 2$ is abundantly expressed in the placenta to protect the fetus from harmful effects of excessive maternal GCs (9). The synthetic GCs Dex and $\beta$-methasone have pharmacodynamic and pharmacokinetic features that are very distinct from those of endogenous Cort. Dex has a longer half-life $(24,51)$ and differs in its abilities to bind and activate the GR and the MR, increasing its potency up to 60 -fold. Of particular relevance for prenatal treatment, these synthetic GCs are poor substrates for $11 \beta$ HSD2 

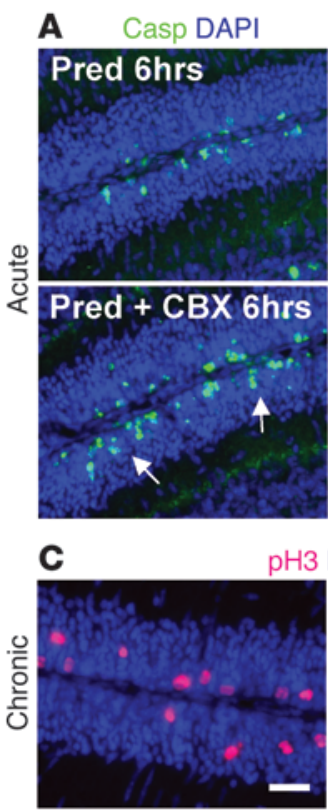

Pred
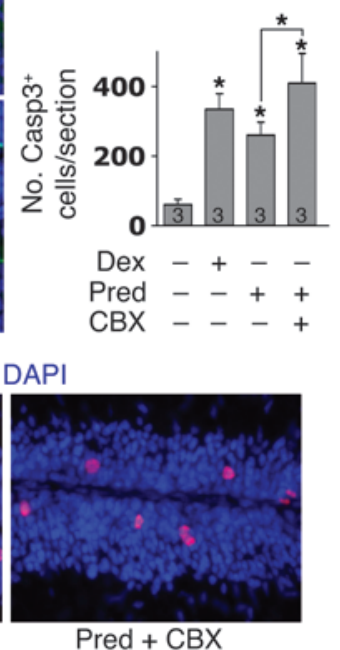

B
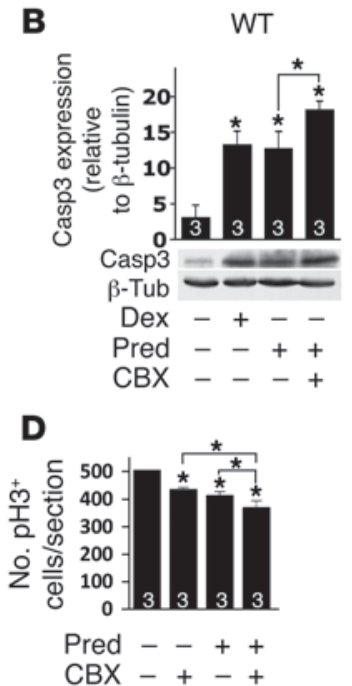

Math1cre,SmoM2

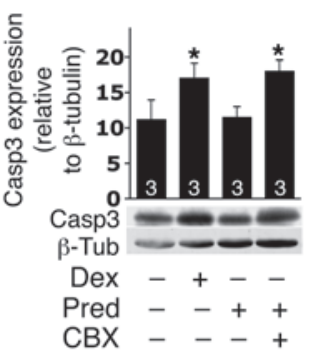

E

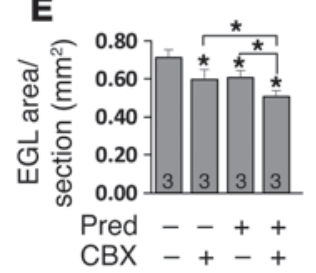

Figure 7

Evidence that $11 \beta \mathrm{HSD} 2$ activity is protective against acute and chronic Pred-induced changes in the cerebellum. (A and B) In WT mice, acute Pred and Dex treatment caused a significant increase in the number of Casp3 ${ }^{+}$cells (arrows), and a further significant increase was observed with Pred in combination with CBX. Original magnification, $\times 400$. (B) Conversely, acutely Pred-treated Math1cre, SmoM2 mice were protected, unless CBX was also administered. Samples were run on the same gel but were noncontiguous. (C and D) With chronic treatment, Pred caused significant inhibition of proliferation; its effects were significantly exacerbated by CBX. Scale bar: $100 \mu \mathrm{m}$. (E) Comparable significant changes were found after measuring the EGL volume. For each group, $n$ is shown within the corresponding bar. Asterisks denote significant differences versus respective vehicle groups (brackets denote comparisons other than with vehicle); exact $P$ values are shown in Results.

and pass through the placenta readily. Conversely, Pred is similar to Cort in terms of its pharmacokinetic and pharmacodynamic features, and it is an effective substrate for 11ßHSD2 (24).

In the neonatal rodent brain, high $11 \beta$ HSD2 expression is observed in the EGL of the cerebellum and in some developing nuclei in the thalamus. Loss of $11 \beta H S D 2$ function results in impaired cerebellar development and a phenotype of anxiety, and this phenotype can be accentuated by administration of exogenous steroids (10). Thus, $11 \beta$ HSD2 evidently serves critical roles in protecting neural precursors from adverse effects of GCs during development. Although CBX has the ability to inhibit both $11 \beta$ HSD2 and $11 \beta H S D 1(52)$, in the present study $11 \beta H S D 1$ expression was never detected in Shh-treated CGNPs with or without Dex administration. CBX is known to inhibit gap junction function (53), and, although it seems unlikely, we cannot rule out that this property might have affected CGNPs in the present study.

We found that $11 \beta H S D 2$ gene expression was induced by ShhSmo signaling, which suggests that Smo activation might serve a neuroprotective function during GC overexposure. Inhibition of $11 \beta$ HSD 2 by CBX augmented the acute proapoptotic effect, as well as the antiproliferative effects, after chronic treatment with Pred. Math1cre,SmoM2 animals were protected against the proapoptotic effects of acute treatment, and the antiproliferative effects of chronic treatment, with Pred and Cort, but not Dex. An 11ßHSD2dependent mechanism was confirmed by treating Math1cre,SmoM2 animals with Pred in combination with CBX. Thus, Smo-induced $11 \beta$ HSD 2 upregulation is protective against the proapoptotic effects of $11 \beta$ HSD2-sensitive GCs.
Clinical implications. The synthetic GCs Dex and $\beta$-methasone are routinely administered to fetuses at risk of premature delivery in order to promote lung maturity, and long-term follow-up studies have established that one course of antenatal treatment is safe and effective without adverse cognitive side effects $(1,2)$. Even multiple courses of antenatal GC treatment do not appear to confer significant neurodevelopmental risk at 2-3 years of age $(45,54)$, although school-age follow-up studies are required to fully assess this issue. In contrast, many studies show that use of neonatal (i.e., postnatal) treatment with Dex leads to motor and intellectual deficits $(3,4,6,20)$.

Our data can be extrapolated into the proposal that use of Dex should be entirely avoided in neonates and infants. Not only can Cort and Pred confer equal therapeutic benefit, but the 11ßHSD2sensitive GCs are in principle less neurotoxic, a view supported by recent studies (55). Small-molecule agonists of Shh signaling have recently been reported to augment cerebellar growth in a mouse model of Down syndrome (56). Further work is needed to evaluate the neuroprotective utility of this approach to promote Hedgehog signaling in the setting of pharmacological or stress-related GCinduced neonatal brain injury.

\section{Methods}

Animals. All animal procedures were reviewed and approved by the IACUC of

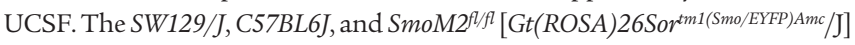
mouse lines were obtained from The Jackson Laboratory. Math1cre transgenic animals that carry bacteriophage P1 cre recombinase under control of a 1.4-kb upstream Math1 enhancer element have previously been described (18). 


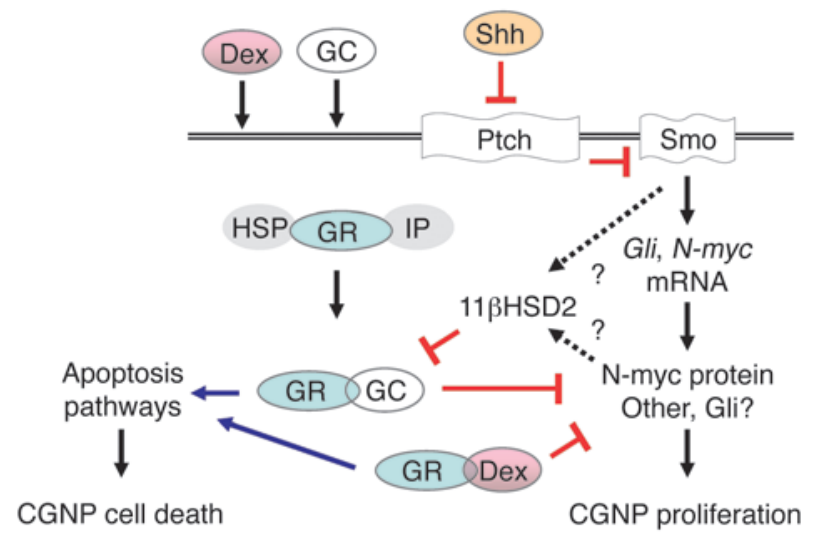

Acute GC treatment only

Acute and chronic GC treatment

\section{Figure 8}

Model for cross-antagonistic interactions of Hedgehog signaling and acute/chronic GC signaling in developing CGNPs. Shh-Smo activation in proliferating CGNPs promotes cell cycle progression and induces $11 \beta H S D 2$ expression, directly or indirectly, through regulation of its downstream activators N-Myc, Gli, and possibly others. In this respect, Shh-Smo signaling is protective against the acute proapoptotic and chronic antiproliferative effects of $11 \beta \mathrm{HSD} 2$-sensitive GCs such as Pred and Cort, but not Dex or $\beta$-methasone. HSP, heat shock protein; IP, immunophillin.

To increase levels of Shh-Smo signaling in CGNPs, the Math1cre strain was intercrossed with the $S m o M 2^{l / f l}$ mice. The primers for PCR genotyping of $S m o M 2^{f / f l}$ mice were described previously (57). The Math1cre allele was detected using internal cre primers (forward, $5^{\prime}$-TCCGGGCTGCCACGACCAA-3'; reverse 5'-GGCGCGGCAACACCATTTT-3').

Postnatal GC administration. On P0.5, C57BL6J or Math1cre,SmoM2 pups received daily i.p. injections of Dex $(0.1 \mu \mathrm{g} / \mathrm{g}$, product no. D6645; SigmaAldrich), Pred (0.67 $\mu \mathrm{g} / \mathrm{g}$, product no. P0152; Sigma-Aldrich), Cort $(0.67 \mu \mathrm{g} / \mathrm{g}$, product no. C2505; Sigma-Aldrich), CBX (100 $\mu \mathrm{g} / \mathrm{g}$, product no. C4790; Sigma-Aldrich), or Pred in combination with CBX, whereas controls received equivalent volumes of saline vehicle. GCs were first dissolved in $100 \%$ ethanol in the range of $3.13-62.50 \mathrm{mM}$, which equals approximately $1.2-24.5 \mathrm{mg} / \mathrm{ml}$, depending on GC type, and were further diluted in saline for use in vivo or culture media for use in vitro. The administration solution contained $0.1 \%-0.3 \%$ of the ethanol stock solution, a standard concentration that had no effect on the viability of CGNPs and has been previously used $(58,59)$. Circulating Dex and Pred serum concentrations were measured using an ELISA kit for Dex and Pred (CER). All pups were weighed daily until sacrifice at P7. On P7, pups were perfused with $4 \%$ paraformaldehyde, or their brain/cerebellum was freshly dissected to determine the wet weight.

Thymidine analogs. To achieve equimolar delivery, solutions of IdU (product no. 100357-05; ICN) or CldU (product no. 57830; Sigma-Aldrich) were prepared as previously described by Vega and Peterson (25). At P5, $42.5 \mu \mathrm{g} / \mathrm{g}$ CldU was administered to the pups, which was followed by i.p. injection of either Dex or saline $2 \mathrm{~h}$ after. The following day, P6, all the pups received $57.5 \mu \mathrm{g} / \mathrm{g} \mathrm{IdU}$, and were perfused $24 \mathrm{~h}$ thereafter.

CGNP primary cell culture and Western blot. Primary cultures of P4 and P5 SW129/J mouse CGNPs were established as described previously (16). Cultures were maintained in serum-free medium containing only vehicle or Shh for $24 \mathrm{~h}$ prior to treatments. Dex was dissolved in 100\% ethanol and diluted with culture medium.
To detect proteins by immunoblotting, nondenaturing lysates were prepared from CGNPs as described previously (60). Immunoblots were incubated overnight at $4^{\circ} \mathrm{C}$ in the following primary antibodies: cyclin D1 (Neomarkers Ab-3); cyclin D2 (catalog no. sc-593; Santa Cruz Biotechnology Inc.); $\beta$-tubulin (product no. T4026; Sigma-Aldrich); GR (catalog no. sc-1004; Santa Cruz Biotechnology Inc.); N-Myc (product no. OP13; Calbiochem); Zic, rabbit polyclonal (gift from R. Segal, Dana-Farber Cancer Institute, Boston, Massachusetts, USA). Subsequently, immunoblots were developed using HRP-conjugated anti-rabbit (Pierce) or anti-mouse (Jackson ImmunoResearch) secondary antibodies and ECL reagents (Amersham).

Immunocytochemistry and TUNEL assay. For immunocytochemistry, coverslips (12 mm; Fischer) coated in poly-L-ornithine (product no. P3655; Sigma-Aldrich) were added to the cultures. The coverslip cultures were fixed in $4 \%$ paraformaldehyde. Antigen retrieval was performed by a microwave treatment in $0.01 \mathrm{M}$ citrate buffer ( $\mathrm{pH}$ 6.0) for $10 \mathrm{~min}$. To block nonspecific binding, specimens were incubated for $1 \mathrm{~h}$ in $5 \%$ normal goat serum, $0.1 \%$ bovine serum albumin, and $0.3 \%$ Triton X-100. The primary antibody incubation was for $1 \mathrm{~h}$ at room temperature and was continued overnight at $4^{\circ} \mathrm{C}$. The following primary antibodies were used: Zic, rabbit polyclonal (gift from R. Segal); pH3 (product no. 9706; Cell Signaling); cleaved Casp3 (product no. 9661; Cell Signaling); calbindin (product no. C8666; Sigma-Aldrich); BrdU (product no. 347580, which also reacts with IdU; BD); BrdU (product no. OBT0030G, which also reacts with CldU; Accurate). The following day, samples were washed, incubated for $1 \mathrm{~h}$ in secondary antibodies (Alexa Fluor 488-conjugated anti-mouse and/or Alexa Fluor 555-conjugated anti-rabbit; Invitrogen), counterstained with DAPI (dihydrochloride; Calbiochem), and mounted in Fluoromount-G aqueous mounting medium (SouthernBiotech). TUNEL assay was performed using the ApopTag Fluorescein In Situ Apoptosis Detection kit (product no. S7110; Chemicon). Sections were counterstained with DAPI and mounted in Fluoromount-G aqueous mounting medium.

In situ hybridization. J.R. Seckl (University of Edinburgh, Edinburgh, United Kingdom), O.C. Meijer (Leiden/Amsterdam Centre for Drug Research, Leiden, The Netherlands), A.L. Joyner (Skirball Institute, New York, New York, USA) and A.P. McMahon (Harvard University, Cambridge, Massachusetts, USA) generously provided antisense probe constructs for 11 1 HSD2, $M R$, Gli1, and Shh, respectively. Digoxigenin-labeled antisense RNA probes were made using plasmid DNA as the template and SP6, T3, or T7 as the RNA polymerase (Roche). In situ hybridization with frozen sections was performed according to standard protocols. Briefly, brain sections were hybridized overnight with labeled RNA probes at $65^{\circ} \mathrm{C}$; washed twice in $0.2 \times \mathrm{SSC}(1 \times \mathrm{SSC}$ is $0.15 \mathrm{M} \mathrm{NaCl}$ plus $0.015 \mathrm{M}$ sodium citrate), $\mathrm{pH} 4.5$, and $0.1 \%$ Tween 20 at $65^{\circ} \mathrm{C}$; washed twice in MBST buffer, $\mathrm{pH} 7.5$, containing $100 \mathrm{mM}$ maleic acid, $150 \mathrm{mM} \mathrm{NaCl}_{2}, 2 \mathrm{mM}$ levamisole, and $0.1 \%$ Tween 20; blocked in MBST with 2\% BM blocking agent (Roche) and 20\% sheep serum; and incubated with alkaline phosphatase-labeled anti-digoxigenin antibodies (diluted 1:2,500 in 2\% serum; Roche) for $2 \mathrm{~h}$. Sections were washed, and color was visualized using BM purple (Roche).

$R T-P C R$. Total RNA was isolated from primary cultures from CGNPs and whole cerebella. Tissue was homogenized in $750 \mu \mathrm{l}$ TRIzoL (Invitrogen) at room temperature over $5 \mathrm{~min}$. Next, $150 \mu \mathrm{l}$ of chloroform was added and incubated for $3 \mathrm{~min}$ at room temperature. The homogenates were centrifuged at $12,000 \mathrm{~g}$ for $15 \mathrm{~min}$. The aqueous phase was collected and precipitated with $350 \mu \mathrm{l}$ isopropanol. The precipitate was collected by centrifugation at $12,000 \mathrm{~g}$ for $15 \mathrm{~min}$, washed with $70 \%$ ethanol, centrifuged at $12,000 \mathrm{~g}$ for $10 \mathrm{~min}$, and resuspended in $100 \mu \mathrm{l}$ RNase-free $\mathrm{H}_{2} \mathrm{O}$. Before continuing with the RT-PCR, RNA was cleaned up with an RNeasy Kit (product no. 74104; Qiagen). RT-PCR was performed on isolated RNAs with an Advantage RT-for-PCR Kit (product no. 639505; Clontech) with random hexamer primers. PCR was performed with Titanium Taq DNA polymerase (product 
no. 639209; Clontech). The following primers were used: N-myc forward, 5'-GGGGGCTCAGGCTCTTCGCTTTTG-3'; N-myc reverse, 5'-CCCGCCGTGGTCTTCCCCTTCC-3'; 11ßHSD2 forward, 5'-GCCCGTGCACGTGCTCAATGTA-3'; 11ßHSD2 reverse, 5'-ACTGGCCTGTGGGGTCTGGTTA-3'; 11ßHSD1 forward, 5'-TTGCGTAGAGCTGTGCCTTTGAT-3'; 11ßHSD1 reverse, 5'-GGCGGACTGGACATGCTTATTCT-3'; Gli1 forward, 5'-ACAGCGGGGGCAGAAGTCG-3'; Gli1 reverse, 5'-CCTCAGCCCCAGTATCCCCAGTCG- 3 '. For $\beta$-actin, the Mouse $\beta$-Actin Control Amplimer Set (product no. 639007; Clontech) was used. Typical PCR conditions were as follows: initial denaturation at $95^{\circ} \mathrm{C}$ for $1 \mathrm{~min}$, followed by 28 cycles of denaturation at $94^{\circ} \mathrm{C}$ for $45 \mathrm{~s}$, annealing at $60^{\circ} \mathrm{C}$ for $45 \mathrm{~s}$, and extension at $70^{\circ} \mathrm{C}$ for $2 \mathrm{~min}$ and a final extension at $72^{\circ} \mathrm{C}$ for $7 \mathrm{~min}$ using Stratagene RoboCycler Gradient 96 temperature cycler with Hot Top Assembly. The products were analyzed on $2 \%$ agarose gels.

Sample size and quantification. To calculate the surface area of the EGL, cresyl violet-stained sections were photographed using a Nikon Eclipse E600 microscope equipped with a SPOT digital camera. Tiff files were transferred to the public domain program Object-Image, an extended version of NIH Image (http://simon.bio.uva.nl). The EGL was outlined, and the surface area was measured. The mean EGL area per section from 1 animal was determined in $\mathrm{mm}^{2}$ from measurements of 4 parasagittal sections from the midline region of the cerebellum. In the adjacent slides, the mean total number of $\mathrm{PH}^{+}$, $\mathrm{Casp}^{+}$or $\mathrm{TUNEL}^{+}$cells per section was determined. CldU, IdU, and Zic1 triple-labeled sections were analyzed using a Leica SP5 confocal microscope.

In vitro experiments were repeated using pups from at least 4 separate litters. For immunochemistry experiments, 2 coverslips per condition were used for each litter. Immunofluorescently stained coverslips were evalu- ated using a Nikon Eclipse $E 600$ microscope with a $\times 40$ objective. The total number of mitotic (i.e., $\mathrm{pH}^{+}$) cells in 10 microscopic fields was assessed for each sample; vehicle-treated cultures had more than 100 cells per field. To determine the relative change in mitosis at different doses of Dex, the number of mitotic cells was expressed as a percentage of total mitotic cells in the vehicle-treated condition.

Statistics. Statistical analysis was performed using an unpaired Student's $t$ test with a 2-tailed $P$ value, or using ANOVA with Tukey's post-hoc test for multiple comparisons. Unless otherwise indicated, Student's $t$ test was used. Differences were considered significant when the $P$ value was less than 0.05 .

\section{Acknowledgments}

The authors are grateful to Sovann Kaing and Michael Wong for expert technical assistance and to Phil Ballard, Rod Phibbs, and Donna Ferrerio for helpful comments. V.M. Heine thanks the Netherlands Organization for Scientific Research (NWO) for a TALENT-stipend. This work was supported by grants from the March of Dimes Foundation and NIH (to D.H. Rowitch). D.H. Rowitch is a Howard Hughes Medical Institute Investigator.

Received for publication June 2, 2008, and accepted in revised form November 26, 2008.

Address correspondence to: David H. Rowitch, Departments of Pediatrics and Neurosurgery and Howard Hughes Medical Institute, Institute for Regeneration Medicine, UCSF, 513 Parnassus Avenue, San Francisco, California 94143, USA. Phone: (415) 476-7242; Fax: (415) 476-9976; E-mail: rowitchd@peds.ucsf.edu.
1. Liggins, G.C., and Howie, R.N. 1972. A controlled trial of antepartum glucocorticoid treatment for prevention of the respiratory distress syndrome in premature infants. Pediatrics. 50:515-525.

2. Dalziel, S.R., et al. 2005. Antenatal exposure to betamethasone: psychological functioning and health related quality of life 31 years after inclusion in randomised controlled trial. BMJ. 331:665.

3. Murphy, B.P., et al. 2001. Impaired cerebral cortical gray matter growth after treatment with dexamethasone for neonatal chronic lung disease. Pediatrics. 107:217-221.

4. Baud, O. 2004. Postnatal steroid treatment and brain development. Arch. Dis. Child. Fetal Neonatal Ed. 89:F96-F100.

5. Bodensteiner, J.B., and Johnsen, S.D. 2005. Cerebellar injury in the extremely premature infant: newly recognized but relatively common outcome. J. Child Neurol. 20:139-142.

6. Yeh, T.F., et al. 2004. Outcomes at school age after postnatal dexamethasone therapy for lung disease of prematurity. N. Engl. J. Med. 350:1304-1313.

7. Beato, M., and Sanchez-Pacheco, A. 1996. Interaction of steroid hormone receptors with the transcription initiation complex. Endocr. Rev. 17:587-609.

8. Reul, J.M., and de Kloet, E.R. 1985. Two receptor systems for corticosterone in rat brain: microdistribution and differential occupation. Endocrinology. 117:2505-2511.

9. Holmes, M.C., and Seckl, J.R. 2006. The role of 11 beta-hydroxysteroid dehydrogenases in the brain. Mol. Cell. Endocrinol. 248:9-14.

10. Holmes, M.C., et al. 2006. 11beta-Hydroxysteroid dehydrogenase type 2 protects the neonatal cerebellum from deleterious effects of glucocorticoids. Neuroscience. 137:865-873.

11. Slotkin, T.A., Kreider, M.L., Tate, C.A., and Seidler, F.J. 2006. Critical prenatal and postnatal periods for persistent effects of dexamethasone on serotonergic and dopaminergic systems. Neuropsychopharmacology. 31:904-911.
12. Noguchi, K.K., et al. 2008. Acute neonatal glucocorticoid exposure produces selective and rapid cerebellar neural progenitor cell apoptotic death. Cell Death Differ. 15:1582-1592.

13. Wechsler-Reya, R.J., and Scott, M.P. 1999. Control of neuronal precursor proliferation in the cerebellum by Sonic Hedgehog. Neuron. 22:103-114.

14. Adams, R.D., Victor, M., and Ropper, A.H. 1997. Principles of neurology. 6th edition. McGraw-Hill. New York, New York, USA. 1618 pp.

15. Kenney, A.M., Cole, M.D., and Rowitch, D.H. 2003 Nmyc upregulation by sonic hedgehog signaling promotes proliferation in developing cerebellar granule neuron precursors. Development. 130:15-28.

16. Kenney, A.M., Widlund, H.R., and Rowitch, D.H. 2004. Hedgehog and PI-3 kinase signaling converge on Nmyc1 to promote cell cycle progression in cerebellar neuronal precursors. Development. 131:217-228.

17. Corrales, J.D., Rocco, G.L., Blaess, S., Guo, Q., and Joyner, A.L. 2004. Spatial pattern of sonic hedgehog signaling through Gli genes during cerebellum development. Development. 131:5581-5590.

18. Schuller, U., et al. 2007. Forkhead transcription factor FoxM1 regulates mitotic entry and prevents spindle defects in cerebellar granule neuron precursors. Mol. Cell. Biol. 27:8259-8270.

19. Tsuneishi, S., et al. 1991. Effects of dexamethasone on the expression of myelin basic protein, proteolipid protein, and glial fibrillary acidic protein genes in developing rat brain. Brain Res. Dev. Brain Res. 61:117-123.

20. Parikh, N.A., et al. 2007. Postnatal dexamethasone therapy and cerebral tissue volumes in extremely low birth weight infants. Pediatrics. 119:265-272.

21. Chen, Y.T., Collins, L.L., Uno, H., and Chang, C. 2005. Deficits in motor coordination with aberrant cerebellar development in mice lacking testicular orphan nuclear receptor 4. Mol. Cell. Biol. 25:2722-2732.

22. Falluel-Morel, A., Tascau, L.I., Sokolowski, K., Brabet, P., and Dicicco-Bloom, E. 2008. Granule cell survival is deficient in PAC1(-/-) mutant cerebellum.
J. Mol. Neurosci. 36:38-44.

23. Klein, J.A., et al. 2002. The harlequin mouse mutation downregulates apoptosis-inducing factor. Nature. 419:367-374.

24. Rupprecht, R., et al. 1993. Pharmacological and functional characterization of human mineralocorticoid and glucocorticoid receptor ligands. Eur. J. Pharmacol. 247:145-154.

25. Vega, C.J., and Peterson, D.A. 2005. Stem cell proliferative history in tissue revealed by temporal halogenated thymidine analog discrimination. Nat. Methods. 2:167-169.

26. Bohn, M.C., and Lauder, J.M. 1980. Cerebellar granule cell genesis in the hydrocortisone-treated rats. Dev. Neurosci. 3:81-89.

27. Rugerio-Vargas, C., Ramirez-Escoto, M., DelaRosaRugerio, C., and Rivas-Manzano, P. 2007. Prenatal corticosterone influences the trajectory of neuronal development, delaying or accelerating aspects of the Purkinje cell differentiation. Histol. Histopathol. 22:963-969.

28. Romer, J., and Curran, T. 2005. Targeting medulloblastoma: small-molecule inhibitors of the Sonic Hedgehog pathway as potential cancer therapeutics. Cancer Res. 65:4975-4978.

29. Hoeck, W., Rusconi, S., and Groner, B. 1989. Down-regulation and phosphorylation of glucocorticoid receptors in cultured cells. Investigations with a monospecific antiserum against a bacterially expressed receptor fragment. J. Biol. Chem. 264:14396-14402.

30. Corrales, J.D., Blaess, S., Mahoney, E.M., and Joyner, A.L. 2006. The level of sonic hedgehog signaling regulates the complexity of cerebellar foliation. Development. 133:1811-1821.

31. Mao, J., et al. 2006. A novel somatic mouse model to survey tumorigenic potential applied to the Hedgehog pathway. Cancer Res. 66:10171-10178.

32. Zhao, Q., et al. 2002. Identification of genes expressed with temporal-spatial restriction to developing cerebellar neuron precursors by a functional genomic 
approach. Proc. Natl. Acad. Sci. U. S. A. 99:5704-5709. 33. Lindsay, R.S., Lindsay, R.M., Waddell, B.J., and Seckl, J.R. 1996. Prenatal glucocorticoid exposure leads to offspring hyperglycaemia in the rat: studies with the 11 beta-hydroxysteroid dehydrogenase inhibitor carbenoxolone. Diabetologia. 39:1299-1305.

34. Rajan, V., Edwards, C.R., and Seckl, J.R. 1996. 11 beta-Hydroxysteroid dehydrogenase in cultured hippocampal cells reactivates inert 11-dehydrocorticosterone, potentiating neurotoxicity. J. Neurosci. 16:65-70.

35. Jellinck, P.H., Monder, C., McEwen, B.S., and Sakai, R.R. 1993. Differential inhibition of 11 betahydroxysteroid dehydrogenase by carbenoxolone in rat brain regions and peripheral tissues. J. Steroid Biochem. Mol. Biol. 46:209-213.

36. Allin, M.P., et al. 2005. Vermis and lateral lobes of the cerebellum in adolescents born very preterm. Neuroreport. 16:1821-1824.

37. Limperopoulos, C., et al. 2005. Late gestation cerebellar growth is rapid and impeded by premature birth. Pediatrics. 115:688-695.

38. Benesova, O., and Pavlik, A. 1989. Perinatal treatment with glucocorticoids and the risk of maldevelopment of the brain. Neuropharmacology. 28:89-97.

39. Heine, V.M., Maslam, S., Joels, M., and Lucassen, P.J. 2004. Increased P27KIP1 protein expression in the dentate gyrus of chronically stressed rats indicates G1 arrest involvement. Neuroscience. 129:593-601.

40. Goya, L., Maiyar, A.C., Ge, Y., and Firestone, G.L. 1993. Glucocorticoids induce a G1/G0 cell cycle arrest of Con 8 rat mammary tumor cells that is synchronously reversed by steroid withdrawal or addition of transforming growth factor-alpha. Mol. Endocrinol. 7:1121-1132.

41. Jamieson, C.A., and Yamamoto, K.R. 2000. Crosstalk pathway for inhibition of glucocorticoidinduced apoptosis by T cell receptor signaling. Proc. Natl. Acad. Sci. U. S. A. 97:7319-7324.
42. Heine, V.M., Maslam, S., Zareno, J., Joels, M., and Lucassen, P.J. 2004. Suppressed proliferation and apoptotic changes in the rat dentate gyrus after acute and chronic stress are reversible. Eur. J. Neurosci. 19:131-144.

43. Rogatsky, I., Trowbridge, J.M., and Garabedian, M.J. 1997. Glucocorticoid receptor-mediated cell cycle arrest is achieved through distinct cell-specific transcriptional regulatory mechanisms. Mol. Cell. Biol. 17:3181-3193.

44. Sundberg, M., Savola, S., Hienola, A., Korhonen, L., and Lindholm, D. 2006. Glucocorticoid hormones decrease proliferation of embryonic neural stem cells through ubiquitin-mediated degradation of cyclin D1. J. Neurosci. 26:5402-5410.

45. Wapner, R.J., et al. 2007. Long-term outcomes after repeat doses of antenatal corticosteroids. N. Engl. J. Med. 357:1190-1198.

46. [No authors listed]. 2000. Antenatal corticosteroids revisited: repeat courses. NIH Consens. Statement. 17:1-18.

47. Committee on Fetus and Newborn. 2002. Postnatal corticosteroids to treat or prevent chronic lung disease in preterm infants. Pediatrics. 109:330-338.

48. Ericson, J., Briscoe, J., Rashbass, P., van Heyningen, V., and Jessell, T.M. 1997. Graded sonic hedgehog signaling and the specification of cell fate in the ventral neural tube. Cold Spring Harb. Symp. Quant. Biol. 62:451-466.

49. Oliver, T.G., et al. 2003. Transcriptional profiling of the Sonic hedgehog response: a critical role for $\mathrm{N}$-myc in proliferation of neuronal precursors. Proc. Natl. Acad. Sci. U. S. A. 100:7331-7336.

50. Machold, R., et al. 2003. Sonic hedgehog is required for progenitor cell maintenance in telencephalic stem cell niches. Neuron. 39:937-950.

51. Orth, D.N., and Kovacs, W.J. 1998. The adrenal cortex. In Williams textbook of endocrinology. 9 th edition. R.H. Williams, D.W. Foster, H.M. Kronenberg, J.D.
Wilson, and P.R. Larsen, editors. W.B. Saunders. Philadelphia, Pennsylvania, USA. 726-764.

52. Diederich, S., et al. 2002. 11beta-hydroxysteroid dehydrogenase types 1 and 2: an important pharmacokinetic determinant for the activity of synthetic mineralo- and glucocorticoids. J. Clin. Endocrinol. Metab. 87:5695-5701.

53. Davidson, J.S., and Baumgarten, I.M. 1988. Glycyrrhetinic acid derivatives: a novel class of inhibitors of gap-junctional intercellular communication. Structure-activity relationships. J. Pharmacol. Exp. Ther. 246:1104-1107.

54. Crowther, C.A., et al. 2007. Outcomes at 2 years of age after repeat doses of antenatal corticosteroids. N. Engl. J. Med. 357:1179-1189.

55. Rademaker, K.J., et al. 2007. Neonatal hydrocortisone treatment: neurodevelopmental outcome and MRI at school age in preterm-born children. J. Pediatr. 150:351-357.

56. Roper, R.J., et al. 2006. Defective cerebellar response to mitogenic Hedgehog signaling in Down [corrected] syndrome mice. Proc. Natl. Acad. Sci. U. S. A. 103:1452-1456.

57. Jeong, J., Mao, J., Tenzen, T., Kottmann, A.H., and McMahon, A.P. 2004. Hedgehog signaling in the neural crest cells regulates the patterning and growth of facial primordia. Genes Dev. 18:937-951.

58. McGinnis, J.F., and de Vellis, J. 1981. Cell surface modulation of gene expression in brain cells by down regulation of glucocorticoid receptors. Proc. Natl. Acad. Sci. U. S. A. 78:1288-1292.

59. Meijer, O.C., et al. 1998. Penetration of dexamethasone into brain glucocorticoid targets is enhanced in mdr1A P-glycoprotein knockout mice. Endocrinology. 139:1789-1793.

60. Kenney, A.M., and Rowitch, D.H. 2000. Sonic hedgehog promotes $\mathrm{G}(1)$ cyclin expression and sustained cell cycle progression in mammalian neuronal precursors. Mol. Cell. Biol. 20:9055-9067. 